\title{
CLASSIFICATION ANALYSIS ON PHYSICOCHEMICAL PROPERTIES OF COLOURED AND NON-COLOURED WAXY RICE
}

\author{
L. Lu*, W.M. Guo, Z.W. Zhu and B.W. DuAN \\ Rice Product Quality Supervision and Inspection Center, Ministry of Agriculture, China National Rice Research \\ Institute, 310006 Hangzhou. China
}

(Received: 28 August 2013; accepted: 22 November 2013)

Six coloured and six non-coloured waxy rice varieties were analyzed by determining amylose, fat, and protein content, pasting, and thermal properties. Significant differences in protein content as well as pasting properties between coloured and non-coloured waxy rice were identified. It was demonstrated that protein may have a main influence on pasting and thermal properties of waxy rice. In addition, the optimal linear relationship between protein and pasting or thermal properties was found by combining RVA and DSC data using Principal component analysis (PCA). Typical indicators, which can classify coloured and non-coloured waxy rice, could be identified by Hierarchical cluster analysis (HCA). In pasting properties, trough and consistency viscosity were typical indicators; in thermal properties, enthalpy and stop temperature were typical indicators.

Keywords: rice, pasting properties, thermal properties

Rice (Oryza sativa L.) consumed by over half of the world's population is an important cereal crop. Although white rice are consumed widely, there are so many special rice varieties that contain colour pigments, such as red and black rice, which become popular in many Asian countries where coloured rice is often mixed with non-coloured rice in order to enhance the flavour in cooking and used as food colorant commonly (ABDEL-AAL et al., 2006; YosHIDA et al., 2010). Coloured rice is usually regarded as nutritious and functional food. It has been reported that red and black rice have a number of nutritional advantages over common rice, including higher vitamins, minerals, polyphenols, and anthocyanin content (ITANI \& OGAWA, 2004; Suzuki et al., 2004; SAIKIA et al., 2012). Comparison on physicochemical and antioxidative properties of red and black rice varieties from different countries (SoMPONG et al., 2011) has been well-documented. However, pasting properties as well as thermal characteristics of coloured and non-coloured waxy rice were rather seldom taken into consideration. Physicochemical measurement and instrument test were objective and effective methods for evaluating sensory and cooking quality of rice (TAN \& CORKE, 2002).

The main purposes of this study were as follows: (i) to find the differences in physicochemical properties between coloured and non-coloured waxy rice; (ii) to investigate whether the two types of rice could be classified by pasting and thermal indicators using $\mathrm{HCA}$; (iii) to figure out the optimized linear correlation of protein and pasting or thermal properties using PCA.

\footnotetext{
* To whom correspondence should be addressed. Phone: +86-571-63370311; fax: +86-571-63370380; e-mail: luzi0522@163.com
} 


\section{Materials and methods}

\subsection{Samples and preparation}

Twelve indica waxy rice cultivars including six coloured varieties (Red rice- Tengchong Organic-R and General-R; Black rice- Lirenzi, Organic-B and General-B) and six noncoloured varieties (White rice- Taihunuo, Shaonuo, Zhennuo, Jinuo, Zhenuo and Xiannuo) were used in this study. All samples were harvested from the southern cities of China in years 2011 and 2012.

Grains in each plot were collected and dried after harvested for one month. Before testing, all samples packaged in paper bags were stored in the drier of $18 \%$ relative humidity at $5{ }^{\circ} \mathrm{C}$ for one week. The samples were milled to $90 \%$ milling yield by a laboratory polisher. Milled grains were ground to flour in an Udy Cyclone Sample Mill (Model Cyclotec 1093 Sample mill, Tecator Technology, Sweden) with 0.42-mm mesh.

\subsection{Analytical methods}

1.2.1. Chemical analysis. Amylose content (AC) was determined by iodine colorimetry at $620 \mathrm{~nm}$ after adding ethanol, $\mathrm{NaOH}$, and acetic acid using a rice starch as standard. Protein content $(\mathrm{PC})(\mathrm{N} \times 5.95)$ was measured by the Kjeldahl method using a Kjeltec-Foss 2400 Auto-analyzer. Fat content (FC) was measured by the Soxtec method using a Soxtec System HT 1043 Foss Fat Analyzer.

1.2.2. RVA analysis. Pasting properties were obtained by Rapid Visco Analyzer (Model $3 \mathrm{D}$, Newport Scientific, Australia). The $3.0 \mathrm{~g}$ of rice flour sample (14\% moisture) dissolved in $25 \mathrm{ml}$ water, was initially held at $50{ }^{\circ} \mathrm{C}$ for $1 \mathrm{~min}$, then heated to $95{ }^{\circ} \mathrm{C}$ at the rate of $12{ }^{\circ} \mathrm{C} \mathrm{min}{ }^{-1}$ for $2.5 \mathrm{~min}$, cooled to $50^{\circ} \mathrm{C}$ at $12{ }^{\circ} \mathrm{C} \mathrm{min}{ }^{-1}$, and held at $50{ }^{\circ} \mathrm{C}$ for $2.5 \mathrm{~min}$. RVA data include peak viscosity (PV), trough viscosity (TV), final viscosity (FV), breakdown (BD), consistency viscosity (CV), pasting time (PTI), and pasting temperature (PTEP). $\mathrm{PV}$ is the maximum viscosity of gelatinization process. TV is the minimum viscosity at $95{ }^{\circ} \mathrm{C}$ and $\mathrm{FV}$ is the final viscosity at $50^{\circ} \mathrm{C} . \mathrm{BD}=\mathrm{PV}-\mathrm{TV}$ and $\mathrm{CV}=\mathrm{FV}-\mathrm{TV}$.

1.2.3. DSC analysis. A differential scanning calorimeter (DSC, Model Q200, TA Instruments, USA) was used. The sample of 4.0-5.0 mg rice flour was weighed directly into the DSC pan, distilled water was added, then the pans were hermetically sealed, equilibrated at room temperature before heating in DSC, which was calibrated by using an empty pan as reference. The determinations were carried out at a heating rate of $10{ }^{\circ} \mathrm{C} \mathrm{min}{ }^{-1}$ from 40 to $100{ }^{\circ} \mathrm{C}$. Start temperature (Tst), peak temperature (Tp), stop temperature (Tsp) of gelatinization, and enthalpy $(\Delta \mathrm{H})$ estimated by integrating the area between the thermogram and a base line under the peak were determined from DSC thermogram described by FUIITA and co-workers (1993).

\subsection{Statistical analysis}

PCA and HCA (Wei et al., 2011; Zhou \& WANG et al., 2011) were carried out by MATLAB $2011 \mathrm{~b}$ and SPSS 13. Underlying index (UI) is used to characterize the classification by HCA. UI was based on the corresponding similarity coefficient of the same cluster. In the same cluster, the largest UI is a typical indicator that could be of help at the classification. 


$$
\mathrm{UI}^{2}=\frac{\sum \mathrm{r}^{2}}{\mathrm{~m}-1}
$$

where $r$ is the coefficient of the other indicator in the same cluster; $m$ is the number of variables.

\section{Results and discussion}

\subsection{Amylose, fat, and protein content}

Amylose contents of coloured and non-coloured rice varieties were similar, ranged from $1.5 \%$ to $2.0 \%$.

The fat contents of all rice were close to each other.

Distinct difference in PC between coloured and non-coloured rice was found. Coloured rice had higher PC compared to non-coloured (Table 1), even the minimum of coloured was $0.2 \%$ higher than the maximum of non-coloured. However, relative standard deviation (RSD) in $\mathrm{PC}$ of coloured rice was higher than that of non-coloured, $15.7 \%$ and $6.1 \%$, respectively, indicating that non-coloured rice perform stable $\mathrm{PC}$ within varieties. As for coloured rice, three varieties (Lirenzi, Organic-B and General-R) showed high PC $(>10 \%)$, and thus are interesting for high quality food products.

\subsection{Pasting properties}

2.2.1. Difference between coloured and non-coloured waxy rice. It can be seen from Table 1 that there are significantly different tendencies of RVA profiles among waxy rice varieties.

Peak viscosity (PV) of all varieties exceeded 100 RVU, coloured waxy rice showed entirely higher results compared with non-coloured. The higher the PV, the higher the swelling power (SP) of the rice. Since the coloured rice possess higher PV, therefore, they are likely to swell more and absorb more water when compared to the non-coloured. The reason could be attributed to the differences in the structure and non-random branching of the amylopectin (AP) in two types of rice (Li et al., 2008).

Apart from cultivar Organic-R, coloured rice varieties had higher TV and FV than noncoloured ones. FV showed the different nature of the viscous paste formed by the two types of rice, that is, the viscosity of paste formed by coloured rice was obviously higher.

Overall, coloured rice had a little higher BD than non-coloured, except for Taihunuo. The higher the $\mathrm{BD}$, the more palatable the rice variety. Obviously, the coloured waxy rice varieties are more palatable than the non-coloured ones.

Significant difference in CV was not found in coloured and non-coloured rice. Tengchong had the highest CV. Pasting time of all varieties ranged from 4.3 to $6.0 \mathrm{~min}$. As for pasting temperature, all exceeded $70{ }^{\circ} \mathrm{C}$. The highest pasting temperature appeared in coloured rice (Tengchong), while the lowest one in non-coloured rice (Zhenuo).

2.2.2. Typical indicator for classification. The result was presented as a dendrogram (Fig. 1A). Pasting properties were grouped into two clusters: cluster I (TV, PTI, and PTEP) and cluster II (PV, FV, BD, and CV). According to Table 2, in cluster I the UI of TV was the largest and CV was the largest in cluster II. Therefore, trough and consistency viscosity were typical indicators in pasting properties, differentiating the two types of rice. 


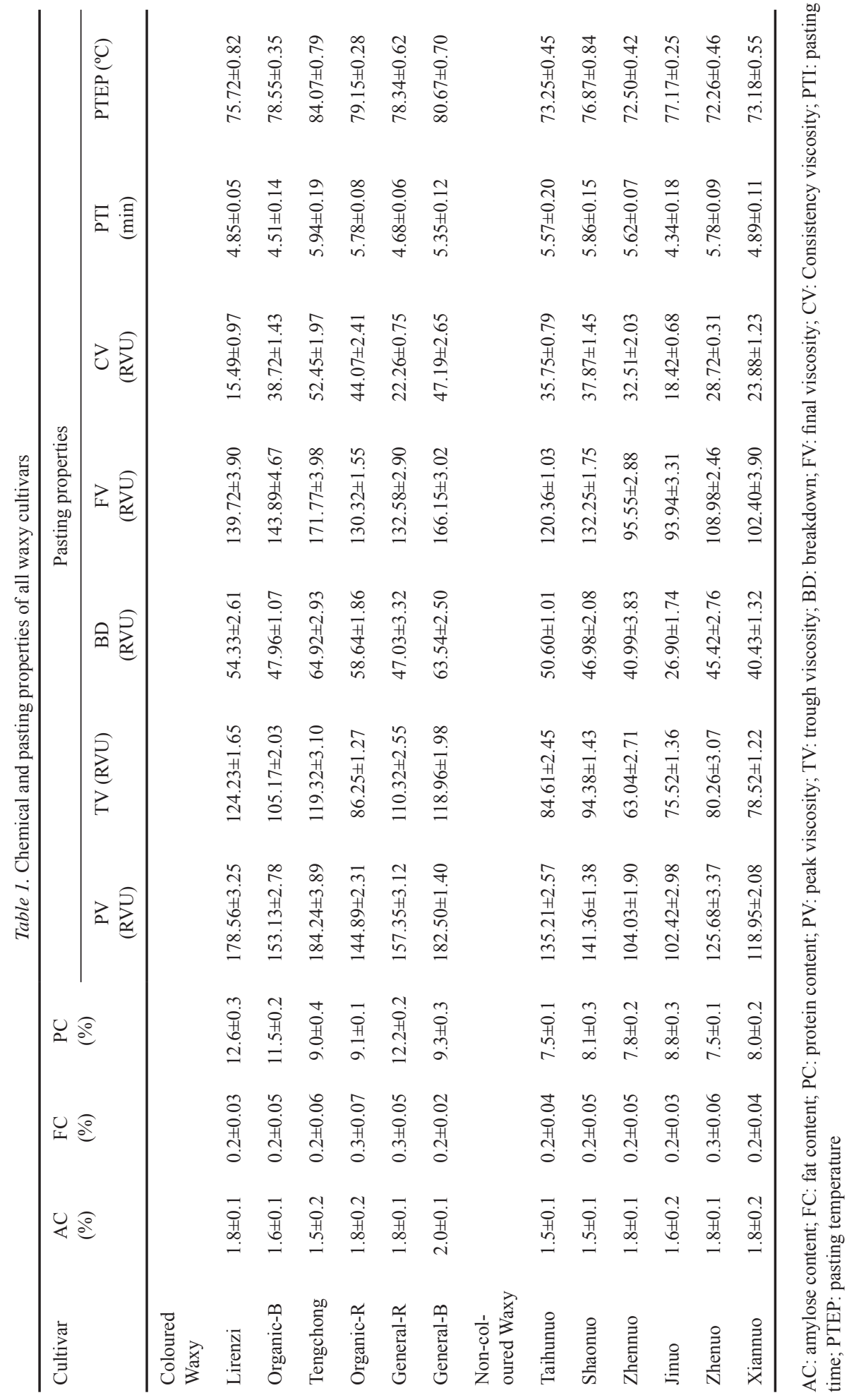




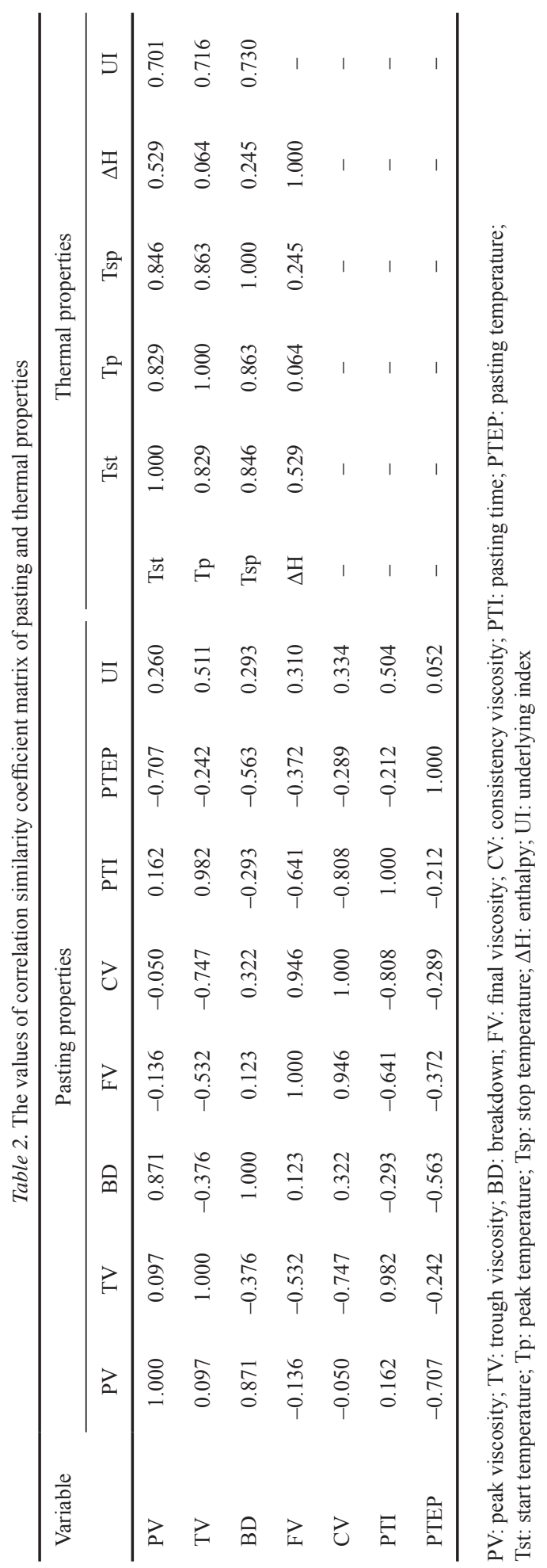


A

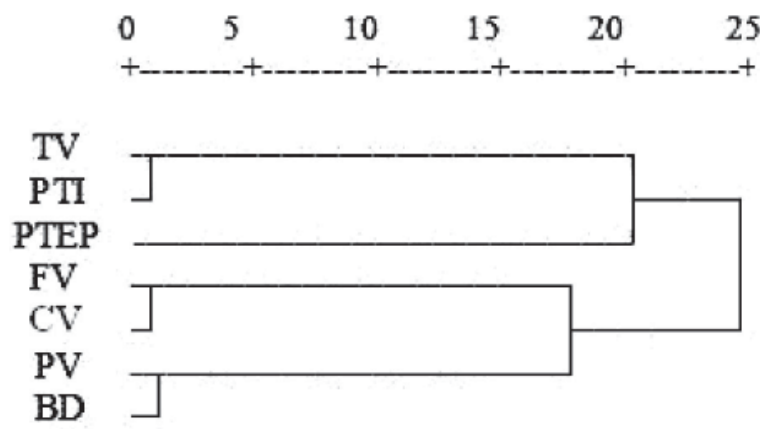

B
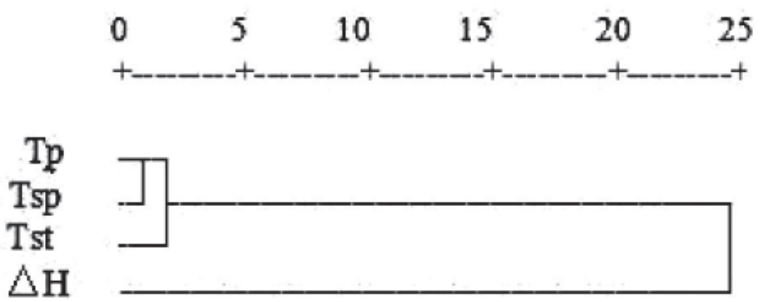

Fig. 1. Tree diagrams of HCA for pasting properties (A) and thermal properties (B) of all rice varieties. Abbreviations: PV: peak viscosity; TV: trough viscosity; BD: breakdown; FV: final viscosity; CV: consistency viscosity; PTI: pasting time; PTEP: pasting temperature; Tst: start temperature; Tp: peak temperature; Tsp: stop temperature; $\Delta \mathrm{H}$ : enthalpy

2.2.3. Effects of proteins on pasting properties. In this study, within coloured varieties, the one with the highest PC had high PV and TV, mediate BD, low FV and CV, whilst the one with the lowest PC had the highest FV, high PV, TV, BD, and CV. There was a disagreement with the previous study by SOMPONG and co-workers (2011), who revealed that viscosities were all low for low amylose rice varieties, while waxy rice mentioned above belongs to the kind of low amylose rice. The disagreement from our results could be attributed to experimental differences. In the previous study, preparation of rice flour was made through a $0.25-\mathrm{mm}$ sieve in contrast with different aperture sieve used in our study. Hence, compared with non-coloured waxy rice varieties, the smaller starch granules of coloured ones may have a greater ability to hold water.

Final viscosities of waxy rice decreased compared to PV, caused by protein hydrolysis rather than by starch hydrolysis (XIE et al., 2008). Protein is the most abundant component of rice grain next to starch, and so has been studied for its potential effects on the sensory evaluation. Eating quality of rice was determined, at least in part, by both the relative proportions of glutelin, prolamin, and protein content (Wu et al., 2009). Effect of protein content on eating and cooking quality of rice varied with the relative proportions of protein fractions. 


\subsection{Thermal properties}

2.3.1. Difference between coloured and non-coloured waxy rice. Subtle differences were observed in the DSC parameters among all samples (Table 3). Start temperature and enthalpy of coloured rice were higher than those of non-coloured rice, the differences between the minimum of coloured and the maximum of non-coloured were $0.7{ }^{\circ} \mathrm{C}$ and $0.32 \mathrm{~J} \mathrm{~g}^{-1}$, respectively.

Table 3. DSC properties of coloured and non-coloured waxy rice varieties

\begin{tabular}{|c|c|c|c|c|}
\hline Cultivar & Tst $\left({ }^{\circ} \mathrm{C}\right)$ & $\operatorname{Tp}\left({ }^{\circ} \mathrm{C}\right)$ & Tsp $\left({ }^{\circ} \mathrm{C}\right)$ & $\Delta \mathrm{H}\left(\mathrm{J} \mathrm{g}^{-1}\right)$ \\
\hline \multicolumn{5}{|c|}{ Coloured Waxy } \\
\hline Lirenzi & $65.17 \pm 1.70$ & $70.87 \pm 1.69$ & $80.51 \pm 1.54$ & $10.52 \pm 1.43$ \\
\hline Organic-B & $67.39 \pm 1.63$ & $73.81 \pm 1.72$ & $82.67 \pm 2.41$ & $8.57 \pm 0.50$ \\
\hline Tengchong & $67.04 \pm 1.74$ & $71.17 \pm 2.55$ & $81.38 \pm 1.06$ & $10.39 \pm 2.14$ \\
\hline Organic-R & $68.78 \pm 1.43$ & $75.43 \pm 1.92$ & $85.08 \pm 2.79$ & $8.49 \pm 1.26$ \\
\hline General-R & $66.58 \pm 1.89$ & $72.35 \pm 1.24$ & $82.06 \pm 1.28$ & $8.65 \pm 1.04$ \\
\hline General-B & $67.16 \pm 1.52$ & $71.59 \pm 2.03$ & $81.03 \pm 2.65$ & $10.24 \pm 1.21$ \\
\hline \multicolumn{5}{|c|}{ Non-coloured Waxy } \\
\hline Taihunuo & $64.47 \pm 1.51$ & $71.96 \pm 1.65$ & $79.80 \pm 2.03$ & $7.20 \pm 0.66$ \\
\hline Shaonuo & $61.93 \pm 1.97$ & $68.00 \pm 1.49$ & $78.17 \pm 3.07$ & $8.05 \pm 1.19$ \\
\hline Zhennuo & $63.81 \pm 1.68$ & $71.06 \pm 1.21$ & $82.46 \pm 4.95$ & $8.17 \pm 1.96$ \\
\hline Jinuo & $62.50 \pm 1.79$ & $69.44 \pm 1.07$ & $78.97 \pm 2.59$ & $7.85 \pm 1.27$ \\
\hline Zhenuo & $63.15 \pm 1.18$ & $71.23 \pm 1.38$ & $79.68 \pm 2.31$ & $7.56 \pm 1.69$ \\
\hline Xiannuo & $62.84 \pm 1.55$ & $70.86 \pm 1.87$ & $78.73 \pm 1.97$ & $8.12 \pm 1.25$ \\
\hline
\end{tabular}

Tst: start temperature; Tp: peak temperature; Tsp: stop temperature; $\Delta H$ : enthalpy

2.3.2. Typical indicator for classification. The resluts (Fig. 1B) show that thermal properties were grouped into two clusters: cluster I $(\Delta \mathrm{H})$, and cluster II (Tst, Tp, Tsp). According to Table 2, in cluster II the UI of Tsp was the largest. Therefore, enthalpy and stop temperature were typical indicators in thermal properties.

2.3.3. Effects of proteins on thermal properties. The value of Tp also either increased or decreased, depending on the protein type and its concentration. The difference in peak temperature could have been due to phase separation between the proteins and the starch molecules (NoIsuwan et al., 2008). It was found that protein fractions affected markedly the thermal behaviour of coloured and non-coloured rice.

High transition temperature and enthalpy have been proved undesirable in terms of eating and cooking quality of rice due to the increased temperature and energy requirement for gelatinization (FuIITA et al., 1993; CHENG et al., 2005). 


\subsection{Optimization of the linear model}

Table 4 shows that the correlation coefficient (CC) acquired by PC3 score from RVA values with $\mathrm{PC}$ of non-coloured ones was the best. However, the $\mathrm{CC}$ acquired by PCA scores from the combination of RVA and DSC values with PC of coloured and total waxy rice was the best. Within coloured or total waxy rice, PC3 had optimal CC, which was 0.9528 and 0.8036 , respectively. The optimal CCs of coloured, non-coloured, and total rice were respectively higher than the best original correlation coefficients. The linear model showed that for noncoloured rice, pasting properties made a greater impact on protein content; for coloured rice, the interaction of pasting and thermal properties made a major influence on protein content.

Table 4. The correlation coefficient value (R) of PCA scores with protein content from pasting and thermal parameters and the combination in coloured and non-coloured waxy rice

\begin{tabular}{|c|c|c|c|c|c|c|c|c|c|c|}
\hline \multirow[t]{2}{*}{ Type } & \multicolumn{3}{|c|}{ RVA } & \multicolumn{3}{|c|}{ DSC } & \multicolumn{3}{|c|}{$\mathrm{RVA}+\mathrm{DSC}$} & \multirow{2}{*}{$\begin{array}{c}\text { Opti- } \\
\text { mal } \\
\text { value }\end{array}$} \\
\hline & PC1 & $\mathrm{PC} 2$ & PC3 & PC1 & PC2 & PC3 & PC1 & PC2 & PC3 & \\
\hline Coloured & 0.7489 & 0.9473 & 0.4208 & 0.4945 & 0.0084 & 0.0020 & 0.8742 & 0.3286 & 0.9528 & 0.9528 \\
\hline $\begin{array}{l}\text { Non- } \\
\text { coloured }\end{array}$ & 0.5474 & 0.7939 & 0.9564 & 0.5871 & 0.6711 & 0.2086 & 0.7527 & 0.5261 & 0.6177 & 0.9564 \\
\hline Total & 0.4141 & 0.7896 & 0.1786 & 0.4332 & 0.5855 & 0.0742 & 0.4421 & 0.1817 & 0.8036 & 0.8036 \\
\hline
\end{tabular}

\section{Conclusions}

In this study, the differences in RVA profiles as well as DSC characteristics among all waxy rice were showed and enlarged by feature extraction using PCA to discriminate coloured and non-coloured rice. The influence of protein on the pasting and thermal properties could explain the difference in the sensory evaluation of rice. Typical indicators that can classify coloured and non-coloured waxy rice could be identified by HCA. Protein has a certain contribution to the interaction of pasting and thermal properties.

\section{References}

Abdel-aAl, E.S., Young, J.C. \& Rabalski, I. (2006): Anthocyanin composition in black, blue, pink, purple, and red cereal grains. J. Agr. Food Chem., 54, 4696-4704.

Cheng, F.M., Zhong, L.J., Wang, F. \& Zhang, G.P. (2005): Differences in cooking and eating properties between chalky and translucent parts in rice grains. Food Chem., 90, 39-46.

Fujita, S., Morita, T. \& Fujiyama, G. (1993): The study of melting temperature and enthalpy of starch from rice, barley, wheat, fortail- and proso-millets. Starch/Starke, 45, 436-441.

Li, Y., Shoemaker, C.F., MA, J., Kim, J.M. \& Zhong, F. (2008): Structure-viscosity relationships for starches from different rice varieties during heating. Food Chem., 106, 1105-1112.

Noisuwan, A., Bronlund, J., Wilkinson, B. \& Hemar, Y. (2008): Effect of milk protein products on the rheological and thermal (DSC) properties of normal rice starch and waxy rice starch. Food Hydrocolloids, 22, 174-183.

Itani, T. \& Ogawa, M. (2004): History and recent trends of red rice in Japan. Jap. J. Crop Sci., 73, 137-147.

Suzuki, M., Kimura, T., Yamagishi, K., Shinmoto, H. \& Yamaki, K. (2004): Comparison of mineral contents in 8 cultivars of pigmented brown rice. Nippon Shokuhin Kagaku Kogaku Kaishi, 51, 424-427. 
Saikia, S., Dutta, H., Saikia, D. \& Mahanta, C.L. (2012): Quality characterisation and estimation of phytochemicals content and antioxidant capacity of aromatic pigmented and non-pigmented rice varieties. Food Res. Int., 46, $334-340$.

Sompong, R., Siebenhandl-ehn, S., Linsberger-martin, G. \& Berghofer, E. (2011): Physicochemical and antioxidative properties of red and black rice varieties from Thailand, China and Sri Lanka. Food Chem., 124, $132-140$.

TAN, Y. \& CoRKe, H. (2002): Factor analysis of physicochemical properties of 63 rice varieties. J. Sci. Food Agric., $82,745-752$

WeI, Z.B., WANG, J. \& YE, L.S. (2011): Classification and prediction of rice wines with different marked ages by using a voltammetric electronic tongue. Biosens. Bioelectron., 26, 4767-4773.

Wu, H.K., Liu, S.J., JiAng, L., Zhang, W.W., Wang, Y.H., Ren, Y.L., Han, X.H. \& Liu, F. (2009): Relationship between protein composition and total protein content and starch RVA profile properties in rice. Chinese J. Rice Sci., 23, 421-426.

Xie, L.H., Chen, N., Duan, B.W., Zhu, Z.W. \& Liao, X.Y. (2008): Impact of proteins on pasting and cooking properties of waxy and non-waxy rice. J. Cereal Sci., 47, 372-379.

Yoshida, H., TомiYama, Y. \& Mizushina, Y. (2010): Lipid components, fatty acids and triacylglycerol molecular species of black and red rices. Food Chem., 123, 210-215.

Zhou, B. \& WANG, J. (2011): Discrimination of different types damage of rice plants by electronic nose. Biosystems Eng, 109, 250-257. 